\title{
A theoretical framework of aesthetic design for a better learning experience on the web- based educational platform
}

\begin{abstract}
With the rapid progression in information and network technologies, web-based educational environment like electronic learning (e-learning) websites and mobile learning (m-learning) websites are increasingly common to be used as a platform for teaching and learning activities. Prior studies in website design have confirmed the crucial role of aesthetics in attracting users, encouraging further exploration and influencing the user performance positively. However, a framework for designing an aesthetic web-based educational platform that should have a positive impact on learning experience is the least explored topic in this area. Therefore, this research aims to propose a framework for designing an aesthetic webbased educational platform, which highlights simplicity, a characteristic that is highly correlated with classical aesthetics, and to study the impact of classical aesthetics on learning experience. The proposed framework is presented and how it should impact learning experience positively through the classical aesthetic design for a web-based educational platform is discussed. Future work involves the verification and validation of the proposed framework through experimental websites and questionnaires with experts as well as users to investigate the impact of this design framework on learning experience. This study hopes to provide a framework that helps in designing an aesthetic web-based educational platform that can impact learning experience positively.
\end{abstract}

Keyword: Classical aesthetics; Framework; Learning experience; Perceived aesthetics; Simplicity; Visual design 